\title{
The Readiness Study of E-Health Adoption Among Regional Public Hospitals; An Empirical Study in Indonesia
}

\author{
Vera Pujani * \\ Department of Management, \\ Andalas University, Padang, Indonesia \\ Rima Semiarty \\ Department of Medical, \\ Andalas University, Padang, Indonesia
}

\author{
Hardisman \\ Department of Medical, \\ Andalas University, Padang, Indonesia \\ Rebi Fara Handika \\ Department of Management, \\ Andalas University, Padang, Indonesia
}

\begin{abstract}
The utilization of information technologies in the health sector has rapidly increased in developed countries and developing countries like Indonesia. Accordingly, this study investigates the role of four readiness categories, including core, engagement, societal, and, structural in adopting e-health in Regional Public Hospitals (RPH) in Padang, Indonesia. This proposed paper presented the survey technique's quantitative research and distributed self-administrated questionnaires to hospital information systems users in the purposive sampling technique. The data obtained were analyzed using Structural Equation Modeling (SEM) and PLS 3.0 software to test hypotheses. Finally, the study tested four hypotheses, and all of them significantly influenced the adoption of e-health in RPH. Additionally, in adopting e-health, core, engagement, societal and structural readiness were identified as important factors that influenced the readiness model of e-health implementation in public hospitals. Some issues are related to adopting e-health in developing countries and public hospitals, especially e-readiness and Information Communication Technology (ICT) planning. The research conclusion and the further research-related parties were described in the final section of this paper.
\end{abstract}

Keywords: E-health adoption, hospital information systems, e-readiness, public hospitals, Indonesia, PLS.

Received: 28 April 2018; Accepted: 21 May 2018; Published: 13 July 2018

\section{INTRODUCTION}

Nowadays, the utilization of the ICT and internet platforms have been belief be able to give benefits and improve the organizational performance [1]. The use of ICT also is identified as tools in operating various activities in service industry for instance the healthcare organization and hospitals. ICT and its applications would have supported health care service delivery based on the requirement of a modern society for better health care services, medical outcomes and keeping in high quality of life.

Emerging information systems and internet in health care system especially in hospitals have been able to increase their attentions to gain benefits including information sharing, reduce costs, and improve the service accessibility of the patient care [2,3]. Again, the modern health care is no doubt to requires the informationintensive activity and the computerization including laboratories, insurance companies and pharmacies [4]. The numerous prior studies have investigated various systems applications in health care institutions and hospitals (ehealth) however, the majority of study conducted related to systems' implementations in western and developed countries. In contrary, the study towards e-health used in

\footnotetext{
${ }^{*}$ Correspondence concerning this article should be addressed to Vera Pujani, Department of Management, Andalas University, Padang, Indonesia. E-mail: verapujani@eb.unand.ac.id

(c) 2018 The Author(s). Published by KKG Publications. This is an Open Access article distributed under a Creative Commons AttributionNonCommercial-NoDerivatives 4.0 International License.
} 
developing countries was less exposed.

The implementation of e-health in Indonesia has started to develop since government regulated by Law No.36 of 2009 on the use of information technology for the health sector, through inter-agency cooperation hospitals, governments, universities, private companies, and providers of telecommunications services. The prior study supposed that the idea of e-readiness in healthcare in developing countries is relatively new and still rare number of empirical studies $[5,6]$.

There is also numerous research of e-health system in hospitals, however, the e-health among public hospitals in regional areas was still less number of the research. Accordingly, the current study aims to test the readiness factors on e-health adoption, since objective of the research is to test the influence of the core, technology, societal, and engagement in adopting e-health in RPHs.

\section{LITERATURE REVIEW}

In the last decades, internet has significantly changed many industries. The Internet is the most important innovation since the development of the printing press. One of the determinants to gain competitiveness of firms in all types of industry is the ability to utilize ICTs [7]. The inherent characteristics in the internet like speed, userfriendliness, low cost and wide accessibility have allowed electronic commerce (referred to e-commerce) to be increasingly used globally, bringing countries together into a global network economy [8]. The extensive use of internet becomes the most enabler to change the business model. For this reason, it has been widely recognized as a new opportunity for all businesses over the globe to achieve their business objectives, in term of pursuing efficiency and quality.

\section{A. Electronic Health Information System (HIS)}

Arising E-health in medical industries is to facilitate the transaction of data processing especially in the medical record from different locations [9, 10]. There are some problems which have not solved yet and contribute to barrier e-health uses in numerous countries. The main problem is related to the system privacy and security of HIS.

The previous studies identified toward the integrated HIS in different contexts and implementation. Not only connecting between internal users in Hospital but also connects to across stake holders in health contexts. [11] presents advance ideas in order to integrate all health data and information across ASEAN countries. This condition related to the large number of patients in every country including Singapore, Malaysia and Indonesia.
Electronic health (e-health) is utilization of electronic communication and information technology to capture, transmit, store, and retrieve health data, information, and knowledge for clinical, educational, and administrative purposes at the local or remote site. E-health has the unique characteristic both for type of interaction for the data and its devices [12]. The type of e-health is using the and store-and-forward, related to information flow processing and storage activities. The data type presents transferred data in the text, voice, image or its combinations. The basic application of e-health is the record and report of patient data, database, service quality evaluation and others [13].

Systematic e-health records provide great opportunities to improve the quality and safety of healthcare, reduce costs, improve continuity and health outcomes for patients, save lives, time and money, make Australian health system more efficient, and provide with equitable access to healthcare. Most public hospitals are in various stages of computerization/digitization [14].

The adoption of e-health system in hospitals refers to using technology system for business activities (ebusiness), accordingly, e-health adoption was derived from business-oriented use [8] related to inter-business communication, coordination's and collaboration. Again, adoption also refers to the nature of system use [15] based on functional and expected purposes. In the meantime, the readiness construct in using e-health system was derived from $[9,16]$ which is measured through the relative status of health institutions and systems' users in adopting ICT and information systems. In addition, core readiness related to the main attribute which need to change in using e-health systems, structural readiness refers to assesses the hospital organization and human resource structures, societal readiness refers to assesses related to external collaboration and healthcare networks, engagement readiness refers to systems providers and willingness to participate using e-health networks, effort expectancy related to facilitate in using e-health systems [16].

\section{B. Readiness Model}

The indicators for core-readiness dealt with the importance of needs assessment, key aspects of planning, and the determinants of accessibility such as appropriateness of technology, and integration of technology with existing services [16]. The indicator for technological structural readiness was included in the tool for managers, and the availability and affordability of required ICT, and the hardware and software needed. Specific technological readiness items dealt with physical access to technology along with determinants of accessibility such 
as affordability and capacity building. The indicator for engagement readiness was included in the tool for healthcare providers, and issues related to the programs and resources to provide training to healthcare providers in using the technology. In addition, the engagement readiness items dealt with the inclusion of healthcare providers in the planning process and determinants of accessibility such as capacity building. The indicator for societal readiness was included in with any existing interaction of the concerned institution with other healthcare institutions in the region and beyond. The tend to the societal readiness items including determinants of accessibility such as relevance of content and sociocultural factors, and addressed the issues of inequity in gender and social classes.

Accordingly, four hypotheses were developed in ehealth adoption that are:

H1: Core readiness influence on e-health adoption.

H2: Engagement readiness influence on e-health adoption.

H3: Societal readiness influence on e-health adoption.

H4: Technological structural readiness influence on ehealth adoption.

\section{METHODS}

This research will be done in Indonesia to facilitate the research objective which is the investigation of the ehealth model based on its users among 3 RPHs in Padang, Indonesia.

The current research had examined e-health adoption model in quantitative and explanatory research through drop-collect survey on its users in 3 RPHs in Padang Indonesia by the purposive sampling technique toward their perspectives in operating information systems. Padang is capital city of West Sumatra Province which located different island with Java Island as the center of economics and government in Indonesia. The data obtained had been analyzed by SEM using SmartPLS program (Partial Least
Square). Analysis using SEM/PLS was conducted to test two different aspect of research model, the first stage was to measure the model through validity test and reliability. The second stage was to measure structural model through hypothesis testing as the empirical research on e-health adoption.

The variable measured are readiness factors including core readiness (8 items), structural readiness (9 item), user societal readiness ( 6 items), engagement readiness (5 items), and adoption (11 items) 5-likert scale.

\section{RESULTS}

The data obtained of this research is the 80-user who has operated the information system/application in conducting their variety jobs in its hospitals. The data analysis was tested by SEM and /PLS software, in the model measurement and structural model were worked.

\section{A. Model Measurement}

The result of this study was data obtained from ehealth users accidentally in 3 RPHs and has been tested for the model measurement including validity and reliability tests. The validity tested was measured by convergent and discriminant validity. The validity test was identified based on the value of outer loading through the process of the algorithm. The indicator is considered valid if it has value of outer loading up 0.70 . However, for loading the $0.50-0.70$ is still accepted [17]. To test the validity, it was used the construct and discriminant validity. The construct validity is measured by identified the value of cross loading, by comparing the indicator correlation of that constructs with the other constructs.

In following Table 1, show that all loading scores have adequate in testing the construct. In the meantime, the cross-loading score identified all of the indicators already have a higher score correlated to the own variable tested rather than other variables, consequently the validity model was presented. 
TABLE 1

CROSS LOADING OF E-HEALTH MODEL

\begin{tabular}{|c|c|c|c|c|c|}
\hline & Adoption & Core Readiness & Engagement Readiness & Societal Readiness & Structural Readiness \\
\hline $\mathrm{AD} 1$ & 0.730716 & 0.206628 & 0.164748 & 0.443149 & 0.269787 \\
\hline AD11 & 0.8202 & 0.382874 & 0.340232 & 0.263269 & 0.268578 \\
\hline $\mathrm{AD} 2$ & 0.816188 & 0.311096 & 0.146354 & 0.40367 & 0.154027 \\
\hline AD3 & 0.876002 & 0.2016 & 0.205347 & 0.445011 & 0.260048 \\
\hline AD4 & 0.864875 & 0.282886 & 0.181372 & 0.429405 & 0.336278 \\
\hline AD5 & 0.747264 & 0.207016 & 0.097329 & 0.38438 & 0.192027 \\
\hline AD6 & 0.773519 & 0.176918 & 0.250598 & 0.448827 & 0.36275 \\
\hline AD7 & 0.860084 & 0.165144 & 0.252274 & 0.259257 & 0.387233 \\
\hline AD9 & 0.79845 & 0.302203 & 0.366234 & 0.360391 & 0.139304 \\
\hline CR1 & 0.235267 & 0.772028 & 0.234706 & 0.110931 & 0.038601 \\
\hline CR2 & 0.186226 & 0.738538 & 0.206496 & 0.094231 & -0.069145 \\
\hline CR3 & 0.255305 & 0.790149 & 0.355342 & 0.109487 & -0.097312 \\
\hline CR4 & 0.277256 & 0.765859 & 0.203454 & 0.130101 & -0.027619 \\
\hline CR5 & 0.260687 & 0.854666 & 0.242704 & 0.127025 & -0.001 \\
\hline CR6 & 0.229949 & 0.80084 & 0.222818 & 0.09339 & -0.05769 \\
\hline CR7 & 0.239052 & 0.829922 & 0.155946 & 0.078188 & -0.038473 \\
\hline CR8 & 0.227371 & 0.709771 & 0.079849 & 0.015888 & -0.04097 \\
\hline EG1 & 0.18388 & 0.1283 & 0.78287 & 0.024662 & 0.061564 \\
\hline EG2 & 0.108531 & 0.068248 & 0.703134 & 0.08084 & 0.020892 \\
\hline EG3 & 0.270921 & 0.281986 & 0.743457 & 0.141523 & 0.008912 \\
\hline EG4 & 0.237132 & 0.17042 & 0.818555 & 0.291271 & 0.040813 \\
\hline EG5 & 0.174954 & 0.315515 & 0.717654 & -0.026672 & -0.129055 \\
\hline $\mathrm{SC} 1$ & 0.482341 & 0.050586 & 0.066756 & 0.798826 & 0.341131 \\
\hline SC2 & 0.293142 & 0.093126 & -0.001374 & 0.819434 & 0.227341 \\
\hline SC3 & 0.36539 & 0.028481 & 0.1854 & 0.876446 & 0.283281 \\
\hline SC4 & 0.415784 & 0.196984 & 0.227787 & 0.85403 & 0.246859 \\
\hline SC5 & 0.377099 & 0.112399 & 0.175518 & 0.839962 & 0.101255 \\
\hline SC6 & 0.359474 & 0.128273 & 0.098388 & 0.756642 & 0.261031 \\
\hline ST1 & 0.161975 & 0.024739 & -0.042952 & 0.128615 & 0.73757 \\
\hline ST2 & 0.269719 & 0.037949 & 0.041732 & 0.339676 & 0.853412 \\
\hline ST3 & 0.245685 & -0.043242 & 0.002607 & 0.259415 & 0.887961 \\
\hline ST4 & 0.201765 & -0.031964 & -0.012243 & 0.199508 & 0.896189 \\
\hline ST5 & 0.308671 & -0.002045 & 0.012589 & 0.286005 & 0.904992 \\
\hline ST6 & 0.290702 & -0.047479 & -0.016085 & 0.268897 & 0.914045 \\
\hline ST7 & 0.295757 & -0.07712 & -0.003809 & 0.225346 & 0.897747 \\
\hline ST8 & 0.304813 & -0.044995 & 0.054103 & 0.326416 & 0.879571 \\
\hline ST9 & 0.399538 & -0.115286 & -0.019706 & 0.27867 & 0.911994 \\
\hline
\end{tabular}

The discriminant validity is identified as the value of cross-loading and also can be seen by comparing the square root of Average Variant Extracted (AVE) in terms of correlation between latent variables.

The AVE value of every construct, it should be greater than 0.5 (Table 2) as the convergent validity. In the meantime, discriminant validity presented by the value of one construct must be higher loading to its construct rather than correlated with other construct in latent variables correlation (Table 3).

The comparison of the square roots AVE of every variable in the diagonal element to correlate with other variables. In Table 3 shows that each of square root $\mathrm{s}$ of AVE for the variable is bigger than correlation among other variables. Accordingly, it can be concluded that the latent variable has a good discriminant validity. 
TABLE 2

OVERVIEW OF E-HEALTH MODEL

\begin{tabular}{llllll}
\hline & & & & & \\
& AVE & Composite Reliability & $R$ Square & Cronbach Alpha & Communality \\
\hline & & & & & \\
Adoption & 0.658025 & 0.945218 & 0.358229 & 0.934431 & 0.658025 \\
Core Readiness & 0.614586 & 0.927097 & 0.909987 & 0.614586 \\
Engagement Readiness & 0.569014 & 0.868081 & 0.81631 & 0.569014 \\
Social Readiness & 0.680861 & 0.927389 & 0.90619 & 0.680861 \\
Structural Readiness & 0.769974 & 0.967763 & 0.962705 & 0.769974 \\
\hline
\end{tabular}

TABLE 3

LATENT VARIABLE CORRELATION

\begin{tabular}{lcclll}
\hline & Adoption & Core Readiness & $\begin{array}{l}\text { Engagement } \\
\text { Readiness }\end{array}$ & $\begin{array}{l}\text { Societal } \\
\text { Readiness }\end{array}$ & $\begin{array}{l}\text { Structural } \\
\text { Readiness }\end{array}$ \\
\hline Adoption & $\mathbf{0 . 8 1 1 1 8 8}$ & & & & \\
Core Readiness & 0.307847 & $\mathbf{0 . 7 8 3 9 5 5}$ & & & \\
Engagement Readiness & 0.277643 & 0.273836 & $\mathbf{0 . 7 5 4 3 2 1}$ & & \\
Social Readiness & 0.474385 & 0.123045 & 0.156544 & $\mathbf{0 . 8 2 5 1 4 3}$ & \\
Structural Readiness & 0.328448 & -0.045558 & 0.004184 & 0.301308 & $\mathbf{0 . 8 7 7 4 8 2}$ \\
\hline \multicolumn{2}{l}{ * Diagonal elements (bold) are the square roots of AVE } & & &
\end{tabular}

Regarding to reliability tested, it was conducted the extent of the measurement tools related to the accuracy and precision of measurement are consistently. There has presents the Instrument reliability which was determined by the value of cronbach's alpha and composite reliability for each block constructs. Rule of thumb, value of cronbach's alpha and composite reliability must be greater than 0.7 though 0.6 is still accepted. It illustrated on Table 2. toward Cronbach's alpha and composite reliability of each variable were cover the rule of thumb since the value was more than 0.7 .

\section{B. Structural Model}

The measurement of the structural model was identified by conducted hypotheses testing using SmartPLS 3.00 version. The hypothesis tested was shown $t$ statistics value in terms of the significance of paths among variables in the structural model. The value of $t$-statistics for hypotheses was greater than $1.97(5 \%)$ and 1.64. (10\%) significances. As the result, tested relationships between e-health model constructs was showed in Table 4 and Fig. 1 (see Appendix).

TABLE 4

PATH COEFFICIENTS (MEAN, STDEV, $T$-VALUE)

\begin{tabular}{|c|c|c|c|c|c|}
\hline & $\begin{array}{l}\text { Original } \\
\text { Sample }(O)\end{array}$ & $\begin{array}{l}\text { Sample } \\
\text { Mean (M) }\end{array}$ & $\begin{array}{l}\text { Standard } \\
\text { Deviation (STDEV) }\end{array}$ & $\begin{array}{l}\text { Standard } \\
\text { Error (STERR) }\end{array}$ & $\begin{array}{l}t \text { Statistics } \\
(|\mathrm{O} / \mathrm{STERR}|)\end{array}$ \\
\hline Core Readiness $->$ Adoption & 0.231931 & 0.245256 & 0.080351 & 0.080351 & $2.886463 * *$ \\
\hline Engagement Readiness -> Adoption & 0.158212 & 0.178488 & 0.083406 & 0.083406 & $1.896887 *$ \\
\hline Societal Readiness $->$ Adoption & 0.350998 & 0.349672 & 0.089089 & 0.089089 & $3.939872 * *$ \\
\hline Structural Readiness -> Adoption & 0.232594 & 0.240758 & 0.074457 & 0.074457 & $3.123855^{* *}$ \\
\hline
\end{tabular}

The four hypotheses have been tested to investigate the influence readiness factor on e-health model (Table 4). All hypotheses have significant relationships on e-health adoption through readiness factors including core, structural, societal and engagement readiness. The $t$ statistic value were between 1.9 and 3.9 respectively. Consequently, hospitals which is owned by regional government in Indonesia should concerned regarding the readiness in adopting e-health for its hospital. 


\section{DISCUSSION}

This study has investigated the utilization of e-health adoption through readiness factors on hospitals which is owned by the regional government in Padang, Indonesia. The research finding was identified that the readiness factor has influenced in adopting e-health in 3 RPHs based on its user's perspectives.

The adoption e-health by RPHs in Padang is caused by the information systems growth of among hospitals itself, since collaboration with other institutions and other the online activities in delivering services in healthcare for community. In order to adopt information systems in hospital actives, it must concern about readiness about core activities of healthcare services, usability and learning purposes of its hospitals. Again, adopting e-health concern about collaboration and integration with other units in hospitals and other related institutions. In addition, technological structure also should be concerned by hospitals in adopting e-health related to the quality of information, service and systems/networks.

Even though, hospitals owned by regional hospitals in small city in Indonesia as a developing country, however, they should pay attention to be able more concerned working with information systems to support numerous healthcare activities.

The core readiness has a significant influence on ehealth adoption, this results illustrated that to adopt ehealth systems hospitals should prepared related about the needs of information systems for their activities based on the priority and business process. Besides that, preparation of system users to more care and acceptance in using information systems in their works.

The engagement readiness identified the preparation in using the health systems and the ability its users to conduct daily activities, learning process and also then get more benefits. The usefulness in using e-health both is related to in financial and non-financial.

The societal readiness has significant relationship with e-health adoption. There are same indicators to ready in adopting e-health, including having collaboration with others institutions, is bale to share with other units in that hospitals. Again, more concerns related to social-culture and economics community during using e-health in regional government hospitals.

The structural readiness is related to readiness for technology provided which suitable for hardware, software, networking ability and its quality including speedy of networks, services delivery as well reliability. This condition is illustrations that is e-health adoption should be prepared also qualified and suitable technologies.

\section{CONCLUSION}

This study examined the e-health adoption model among three regional government hospitals in Padang, Indonesia. There are 4 hypotheses tested in this research and found that all hypotheses have significant influences in adopting e-health including core, engagement, societal and structural readiness.

The further research will be more explore the influenced factors in adopting e-health whereas examined variable for cultural and behavioral studies especially in developing countries and less health profile countries. There is many topics could be investigated its countries.

\section{ACKNOWLEDGMENT}

The authors are grateful to Indonesian Minister of Research Technology and Higher Education (MenristekDikti-DP2M) giving the financial support of this research as International Research Collaboration grant and Scientific Publication 2018.

\section{REFERENCES}

[1] A. Molla, K. Peszynski, and S. Pittayachawan, "The use of e-business in agribusiness: Investigating the influence of e-readiness and OTE factors," Journal of Global Information Technology Management, vol. 13, no. 1, pp. 56-78, 2010. doi: https://doi.org/10.1080/1097198x.2010.10856509

[2] M.-L. Jung and K. Loria, "Acceptance of Swedish e-health services," Journal of Multidisciplinary Healthcare, vol. 3, p. 55, 2010. doi: https://doi.org/ $10.2147 / j m d h . s 9159$

[3] B. Rist and A. J. Pearce, "Does technology improve athlete engagement in mental training techniques?" International Journal of Health and Medical Sciences, vol. 2, no. 2, pp. 41-47, 2016. doi: https://doi.org/10.20469/ijhms.2.30004-2

[4] C. Kimble, "Business models for e-health: Evidence from ten case studies," Global Business and Organizational Excellence, vol. 34, no. 4, pp. 18-30, 2015. doi: https://doi.org/10.1002/joe.21611

[5] S. Khoja, R. E. Scott, A. L. Casebeer, M. Mohsin, A. Ishaq, and S. Gilani, "e-health readiness assessment tools for healthcare institutions in developing countries," Telemedicine and e-Health, vol. 13, no. 4, pp. 425-432, 2007. doi: https://doi.org/10. 1089/tmj.2006.0064

[6] S. S. Alharbi, "Comparing Australian my health record system implementation with global best practices with recommendations," Journal of Advances in Health and Medical Sciences, vol. 3, no. 2, pp. 
63-74, 2017. doi: https://doi.org/10.20474/jahms3. 2.3

[7] B. Ramdani, D. Chevers, and D. A. Williams, "Smes' adoption of enterprise applications: A technology-organisation-environment model," Journal of Small Business and Enterprise Development, vol. 20 , no. 4, pp. 735-753, 2013. doi: https: //doi.org/10.1108/jsbed-12-2011-0035

[8] E. M. Daniel and D. J. Grimshaw, "An exploratory comparison of electronic commerce adoption in large and small enterprises," Journal of Information Technology, vol. 17, no. 3, pp. 133-147, 2002. doi: https://doi.org/10.1080/0268396022000018409

[9] M. Vitacca, M. Mazzù, and S. Scalvini, "Sociotechnical and organizational challenges to wider e-health implementation," Chronic Respiratory Disease, vol. 6, no. 2, pp. 91-97, 2009. doi: https: //doi.org/10.1177/1479972309102805

[10] R. Kazikhanov, S. R. Kazikhanova, and S. S. Kazakh, "Intensive technology of growth, complex processing of lambs flesh for meat products," Journal of Advances in Health and Medical Sciences, vol. 2, no. 1, pp. 1-9, 2016. doi: https: //doi.org/10.20474/jahms-2.1.1

[11] S. B. Kathayat and N. Rajatheva, "Interest based group management mechanisms for e-learning design using the peer-to-peer technologies," in International Conference on Web Information Systems and Technologies (WEBIST), Setubal, Portugal, 2006.
[12] J. Briggs. (2004) Telemedicine and e-health ICT to make people better more quickly. [Online]. Available: https://bit.ly/2VDsr7F

[13] S. Soegijoko, Y. S. Irawan, and E. Sutjiredjek, "Information \& communication technology-based telemedicine system for public health services in Indonesia," in National Conference on Information \& Communication Technology for Indonesia, Bandung, Indonesia, 2006.

[14] E. W. Coiera, M. R. Kidd, and M. C. Haikerwal, "A call for national e-health clinical safety governance," The Medical Journal of Australia, vol. 196, no. 7, pp. 430-431, 2012. doi: https://doi.org/10.5694/mja12. 10475

[15] B. M. Kalema and M. R. Kgasi, "Leveraging ehealth for future-oriented healthcare systems in developing countries," The Electronic Journal of Information Systems in Developing Countries, vol. 65, no. 1, pp. 1-11, 2014. doi: https://doi.org/10.1002/j. 1681-4835.2014.tb00470.x

[16] S. Khoja, H. Durrani, R. E. Scott, A. Sajwani, and U. Piryani, "Conceptual framework for development of comprehensive e-health evaluation tool," Telemedicine and e-Health, vol. 19, no. 1, pp. 48-53, 2013. doi: https://doi.org/10.1089/tmj.2012.0073

[17] D. Cooper and P. Schindler, "International edition: Business research methods," New Delhi, India: MacGraw-Hill, 2013. 


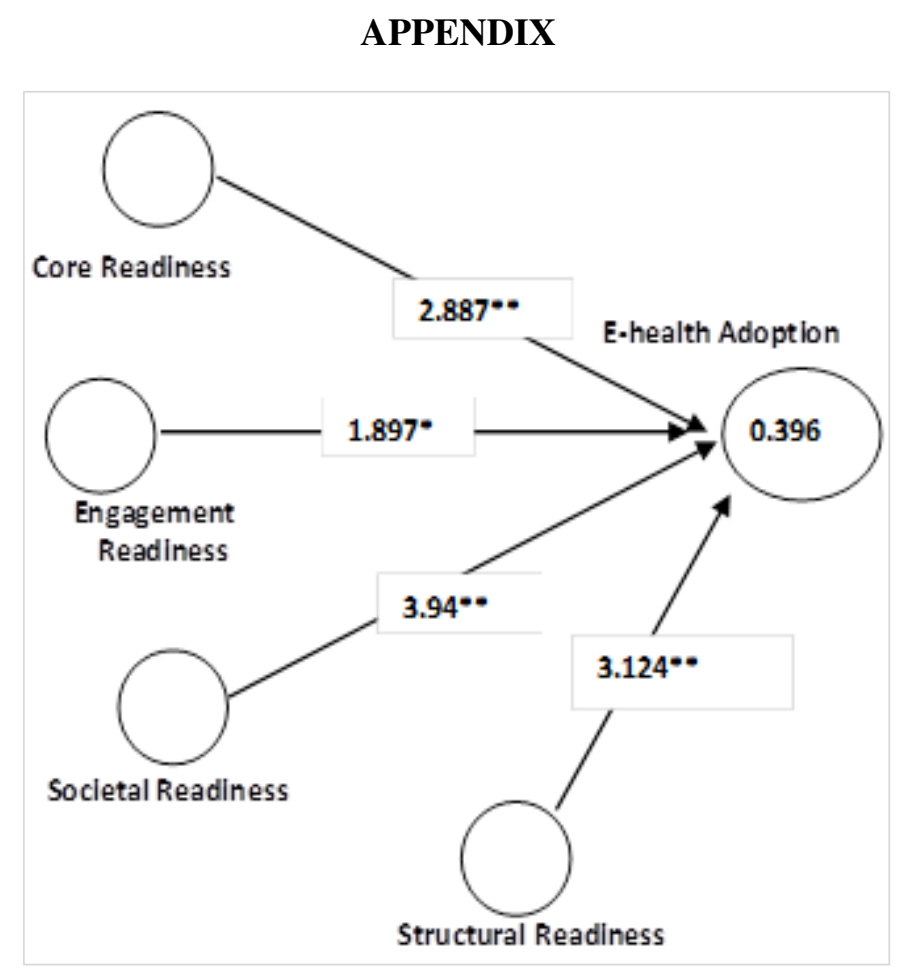

Fig. 1. Structural model of e-health adoption

TABLE 5

INDICATORS OF E-HEALTH ADOPTION

Adoption

AD1 Information on growing

AD2 Stock availability

AD3 Online Registration

AD4 Monitoring service delivery

AD5 Integrated Systems

AD6 Online order

AD7 Doktor Online Schedule

AD8 Integrating System with health government institutions

AD9 Online community

AD10 Integrating access intra divisions/units

AD11 Relevance information

Core Readiness

CR1 Identification of needs

CR2 Dissatisfaction with old Systems

CR3 Awareness

CR4 Comfort with technology

CR5 Trust

CR6 E-health planning

CR7 Integration of technology

CR8 Overall satisfaction
Engagement Readiness

EG1 Usefulness

EG2 Financial benefits

EG3 Reluctance to change

EG4 Continuing learning

EG5 Ability to learn

Societal Readiness

SC1 Collaborate with health institutions

SC2 Sharing information with other institutions

SC3 Social Culture between staff

SC4 Position of Social economics community

SC5 Social culture with community

SC6 Service provided with collaborations

Structural Readiness

ST1 Speedy and network quality

ST2T2 Service and support ICT

ST3 Ability of hardware and software

ST4 Reliability of networks

ST5 Internet accessibility

ST6 Suitable hardware and software

ST7 Training for users 